\title{
Assessing Consumer Preferences for Organic Vegetables: A Case Study in the Mekong Delta, Vietnam
}

\author{
Huynh Viet Khai \\ School of Economics and Business Administration, Can Tho University, Vietnam \\ hvkhai@ctu.edu.vn
}

\begin{abstract}
An increase in consumer's demand for environmental and health quality has generated the movement of organic agriculture in terms of high-value products. Understanding consumer preferences is very necessary and important for policy-makers to design appropriate policies promoting and developing organic agriculture. This study employed a dichotomous choice contingent valuation model to analyze consumer's willingness to pay for organic vegetables in the Mekong Delta, Vietnam. Results indicated that the majority of consumers were interested in organically grown products and willing to pay an average price premium of 59\% for organic vegetables. Consumers concerned about health and food safety were more likely to purchase and those who have high household income and education also accepted to buy organic vegetables with higher price than conventional ones.
\end{abstract}

Keywords: Contingent valuation, willingness to pay, organically grown products

\section{Introduction}

The demand for organically grown produce or organic products has recently been received much attention by consumers as a result of their increasing concern about environmental issues, the nutritional value of food and health issues. Especially, the quality and safety of food attract consumer interest and affect buying behaviour (Tsakiridou et al., 2008; Laroche et al., 2001). As a consequence, production and consumption of organic products have recently been one of the fastest growing food sector and many economists have been increasingly interested in the study of consumer preferences and demand for organics. Organic production is defined as a farming system with mainly using organic manure and avoiding the large utility of fertilizers, pesticides and chemicals. Organic production has a positive impact on the environment such as decreased contamination water and increased soil fertility. Moreover, many studies have proven that consumers have positive perceptions of organic products and are willing to pay a higher price premium for the commonities with organic farming techniques because they think them healthier than conventional ones (Gil et al., 2000).

The contingent valuation (CV) method has been popularly applied to identify consumer utility or preferences of organic commodities in the world. This approach is based on a hypothetical scenario in which respondents are requested through questionnaires to reveal their maximum willingness to pay (WTP) for organic products (Khai, 2014). The study by Gil et al. (2000) applied the CV method with a dichotomous choice to estimate consumer willingness to pay for organic food in Spain. The study showed that consumer was willing to pay a high premium for especially those who concerned about healthy diet and environmental degradation were the most like to buy organic food. Rodriguez et al. (2007) also indicated that Argentinean consumers were willing to pay a price premium from $6 \%$ to $200 \%$ for organic food depending on restricting their acquisition. With the study on consumer willingness to pay for organic produce in the Northeastern U.S., Govindasamy et al. (2006) found out that gender and income were one of the most important factors affecting the willingness to pay for reduced pesticide produce and organic produce, while Tsakiridou et al. (2006) investigated that consumer attitudes and socioeconomic characteristics largely influenced their willingness to pay a substantial extra price to buy organically produced products.

A large number of researches on organic agriculture have been done in Europe and other western countries, but very few in Asia countries (Hai et al., 2013; Roitner-Schobesberger et al., 2008). Searching the literature reviews, little information and studies related to organic products and farming were found in Vietnam. Simmons and Scott (2008) reviewed the trends and prospects for organic agriculture to address agro-food 
system sustainability in Vietnam. The study revealed that organic agriculture in Vietnam was not centered on environmental concerns and was instead driven largely by the demand from export markets. Although Vietnamese consumers had strong concerns on food safety and food quality, the domestic market for organic products have not been developed so much. Mergenthaler et al. (2009) applied the CV approach to analyze consumers' valuation of different vegetable attributes in metropolitan areas of Vietnam. The results showed that consumers were willing to pay an average price premium of $60 \%$ for Chinese mustard free of chemical residues and by $19 \%$ for different convenience attributes of potatoes. The study by Dam et al. (2012) stated that the organic farming has not yet played an important role in the Vietnamese agriculture sector and a lack of specific government policies supported the development of organic farming. The recent study written by Hai et al. (2013) estimated consumers' preference for organic vegetables in Hanoi capital of Vietnam. This study discovered that fifteen percent of the consumers had experiences of using organic vegetables and were willing to pay a premium of $70 \%$ higher for organically produced vegetables. Beside the limited information about organic agriculture provided by previous studies, the aim of this study is to provide more pictures of consumer demand such as attitudes, purchase criteria and behavior towads organic products in the Vietnamese Mekong Delta where there is not so many previous studes related to organic production. The results of the study might be useful in terms of advertising or merchandising strategies for policy makers and concerned people who promote or develop the future market for organically grown products. The paper is structured as follows. The next section describes the theory of CV model applied to estimate the consumer preferences for organic vegetables and the way to collect data. The following section reports the results and some discussions of willingness to pay for organic vegetables. The final section presents the conclusions of the study.

\section{Methodology}

This study used the CV method to identify the consumer preferences for organic vegetables. The CV method first used at the beginning of the 1960s to estimate the benefits of outdoor recreation in Maine backwoods by Robert (1963). After that, Ridker (1971) applied the CV method for air pollution problems. From the 1970s up to now, this $\mathrm{CV}$ approach has been applied by many economists to measure the benefits of a wide variety of goods such as recreation, hunting, water quality, decreased mortality risk from a nuclear power plant accident and toxic waste dumps, etc. (Wattage, 2002). Although there are some arguments related to the correct level of results from the CV method, many economists have agreed that the CV method produces valid and reliable WTP estimates if carefully designed or constructed (e.g., Yao and Kaval, 2008; Venkatachalam, 2004; Carson et al., 2001).

The basic theory of the dichotomous CV approach proposed by Hanemann (1984) is that the idea favored by current $\mathrm{CV}$ practice is to ask each respondent a closed from question, namely whether they would accept to pay a given amount to obtain a given change in their status quo. Hence the answers obtained are the type of 'yes' or 'no', necessitating a theory of how to translate these discrete responses into meaningful WTP estimates (Khai and Yabe, 2011). We suppose that a respondent is asked to consider the change from the status quo $Q^{0}$ to $Q^{1}$, where $Q^{1}$ refers to the quality of the environment and presumably the latter choice is preferable to the former. Denote the indirect utility of respondents as $V(P, Q, I, Z)$, where $P$ is a vector of prices, $I$ is the respondent's income and $Z$ is a vector of respondent characteristics. Then if the respondent is asked whether he would be willing to pay an amount $M$ to obtain $Q^{1}$, his answer would be 'yes' if the following condition holds (where $\operatorname{Pr}$ denotes the probability):

$\operatorname{Pr}(Y e s)=\operatorname{Pr}\left\{V\left(P, Q^{1}, I-M, Z\right)+\varepsilon_{1} \geq V\left(P, Q^{0}, I-0, Z\right)+\varepsilon_{0}\right\}$

$$
=\operatorname{Pr}\left\{V\left(P, Q^{1}, I-M, Z\right)-V\left(P, Q^{0}, I-0, Z\right)+\varepsilon_{1}-\varepsilon_{0} \geq 0\right\}
$$

Where $\varepsilon_{0}$ and $\varepsilon_{1}$ are unobservable components of the utility and identically and independently distributed (i.i.d) random variable with zero mean. If we define $\Delta V=V\left(P, Q^{1}, I-M, Z\right)-V\left(P, Q^{0}, I-0, Z\right)$ and $\gamma=\varepsilon_{1}-$ $\varepsilon_{0}$, and can then write:

$$
\operatorname{Pr}(\text { Yes })=\operatorname{Pr}(\gamma \geq-\Delta V)=1-F_{\gamma}(-\Delta V)=F_{\gamma}(\Delta V)
$$

Where $F_{\gamma}(\Delta V)$ represents the cumulative density function (cdf) of the respondent's true maximum WTP.

This model could be estimated with maximum likelihood. Let $R_{\mathrm{k}}$ be an indicator variable for observation $k$, with:

$$
\operatorname{Pr}(\text { Yes })=\operatorname{Pr}\left(R_{k}=1\right)=\operatorname{Pr}\left(\gamma_{k} \leq \Delta V_{k}\right)=F_{\gamma}\left(\Delta V_{k}\right)
$$




$$
\operatorname{Pr}(N o)=\operatorname{Pr}\left(R_{k}=0\right)=\operatorname{Pr}\left(\gamma_{k} \leq \Delta V_{k}\right)=1-F_{\gamma}\left(\Delta V_{k}\right)
$$

The dichotomous CV technique estimates the mean and median WTPs based on the coefficients related the WTP responses against a constant and the bid $(B I D)$. Additional coefficients $(X)$ of other variables like responses to attitude questions or the respondents' demographic information may also be factored into the model. In this study, the linear log-probit model was employed to analyze the dichotomous choice format of the contingent valuation method. This specification assumes that:

$$
\operatorname{Pr}(Y e s)=F_{\gamma}(\Delta V)=\exp \left(\alpha+\beta_{1} B I D+\beta_{2} X+\varepsilon\right)
$$

Where $\varepsilon \sim$ i.i.d. $N\left(0, \sigma^{2}\right)$ or equivalently:

$$
\ln \left[F_{\gamma}(\Delta V)\right\rfloor=\alpha+\beta_{1} B I D+\beta_{2} X+\varepsilon
$$

Where $\alpha$ and $\beta$ are coefficients to be estimated and BID is the amount of given money the respondents were asked to pay. The corresponding likelihood is:

$$
\log L=\sum_{k=1}^{N}\left\{R_{k} F_{\gamma}\left(\Delta V_{k}\right)+\left(1-R_{k}\right) \ln \left(1-F_{\gamma}\left(\Delta V_{k}\right)\right)\right\}
$$

In this case of the lognormal specification, the conditional mean WTP is calculated as follows (Haab \& McConnell, 2002):

$$
\text { Mean } W T P=E\left\lfloor\exp \left(\alpha+\beta_{1} B I D+\beta_{2} X+\varepsilon\right)\right\rfloor=\exp \left(\frac{-\left(\alpha+\beta_{2} \bar{X}\right)}{\beta_{1}}+\frac{\sigma^{2}}{2}\right)
$$

Whereas the conditional median WTP corresponds to:

$$
\text { Median } W T P==\exp \left(\frac{-\left(\alpha+\beta_{2} \bar{X}\right)}{\beta_{1}}\right)
$$

Data Collection: Primary data were collected by randomly interviewing local residents face-to-face in Can Tho city, the center of the Mekong Delta region. The survey was divided into two main periods. The first period is called as a pilot-survey that is essential elements in any contingent valuation study (Bateman et al., 1995). The aims of this interview are to refine the questionnaire and format bid starting point more clearly and concisely, and also help interviewers get used to and understand the content of the questionnaire. After the interviewers are trained how to ask by using the questionnaire, there are about 18 households interviewed in this period. The revised questionnaire is used in the second period and total 360 respondents are collected. Regarding the structure of the questionnaire, the information or respondents' knowledge about organic agriculture are examined in the first section and then the questions related to the CV method are introduced with the scenarios and benefits of the proposed organic vegetables. Respondents' demographic characteristics and attitude toward environmental issues are included in the final section of the questionnaire.

In this study, the quality of proposed organic vegetables is assumed to be similar to conventional ones and the dichotomous choice contingent valuation method was applied to structure the questionnaire. The payment vehicle is used as a higher premium of organic vegetables respondents are willing to pay compared with the conventional ones assumed to be VND 8,000 (\$0.38) per kg1. Each household was interviewed whether he/she would be willing to buy organic vegetables at a certain price or a given bid value and the answer was 'yes' or 'no'. Six different bid values of VND 9,000, VND 10,000, VND 11,000, VND 12,000, VND 14,000 and VND 16,000 per kg were chosen for the study. These values are equivalent to values in US dollars ${ }^{2}$ of $\$ 0.42, \$ 0.47, \$ 0.52$, $\$ 0.57, \$ 0.66$ and $\$ 0.75$, respectively. Each household was randomly interviewed whether he/she would be willing to buy organic vegetables with one of these bid values and answered whether he/she accepted only one bid value.

\section{Results and Discussion}

After answering a series of questions to assess the information and consumer's knowledge about organic agriculture, the study gave the hypothetical scenario if the proposed organic vegetables were available in a market and asked whether respondents are willing to pay a higher price premium. Table 1 summarizes the results of consumer's willingness to pay and unwillingness to pay for organic vegetables with different bid values. About 54 percent of respondents answered that they were willing to pay a given bid value to support the proposed organic vegetables, while nearly $46 \%$ were not willing to pay. The results show that the percentage of the respondents who are willing to pay for organic vegetables decreases as the bid value

\footnotetext{
${ }^{1}$ This assumed price is estimated averaging the prices of 10 popular vegetables at the time of study.

${ }^{2} 1 \mathrm{USD}=21,210 \mathrm{VND}$ at the date of $25 / 07 / 2014$
} 
increases. Over $78 \%$ of respondents are willing to pay at the bid value of VND 10,000 while only $20 \%$ demanding organic vegetables at the highest premium of VND 16,000.

Table 1: Consumers willing to pay and unwilling to pay for organic vegetables

\begin{tabular}{llllll}
\hline \multirow{2}{*}{ Bid value } & \multirow{4}{*}{ Observation } & \multicolumn{4}{l}{ Answers to the WTP question } \\
\cline { 3 - 6 } & & \multicolumn{2}{l}{ Willingness to Pay } & \multicolumn{2}{l}{ Unwillingness to Pay } \\
\cline { 3 - 5 } & & Number & Percent & Number & Percent \\
\hline 9,000 & 60 & 48 & 63.33 & 22 & 36.67 \\
10,000 & 60 & 36 & 78.33 & 13 & 21.67 \\
11,000 & 60 & 42 & 60.00 & 24 & 40.00 \\
12,000 & 60 & 21 & 70.00 & 18 & 30.00 \\
14,000 & 60 & 12 & 35.00 & 39 & 65.00 \\
16,000 & $\mathbf{3 6 0}$ & $\mathbf{1 9 6}$ & $\mathbf{5 4 . 4 4}$ & $\mathbf{1 6 4}$ & $\mathbf{4 5 . 5 6}$ \\
Total & & &
\end{tabular}

Source: Own estimates; data appendix available from authors.

The one of the most valuable results in a contingent valuation survey is whether the WTP is affected by important variables suggested by economic theory, for example income, education, gender, etc. or whether the coefficients of these variables have the signs with expectations. The variables we believed are of importance are listed in detail in Table 2. On average, surveyed respondents have a household income of VND 4.33 million per month with the most frequent category from VND 3 million to 5 million (40\%), followed by below VND 3 million (32\%), VND 5 million - 7 million (19\%), and over VND 7 million (9\%). Over half (58\%) of the respondents are male and nearly 39 percent of them stated obtaining a university and higher degree. Twenty seven percent of the respondents are housewives, while the rest are either working for salary, self-employed or retired. The majority (69\%) of the respondents stated their current concern on environmental issues, while about thirty four percent of them pay much attention to the health and food safety. The study surveyed about 33\% of the respondents in the center area, while the rest of $67 \%$ in the suburban area of Can Tho city.

Table 2: Descriptive statistics of variables used in the Probit model

\begin{tabular}{llll}
\hline Variables & Description & Mean & Std. Dev. \\
\hline WTP & Willingness to pay for organic vegetables (1= yes, 0 = no) & 0.544 & 0.499 \\
$\ln ($ Bid $)$ & Bid value in natural logarithm & 9.373 & 0.195 \\
Income & Monthly household income of respondents (million VND) & 4.327 & 2.519 \\
Graduate & $\begin{array}{l}\text { Dummy variable equaling 1 for graduate or higher and 0 for } \\
\text { otherwise }\end{array}$ & 0.386 & 0.488 \\
Housewife & Dummy variable equaling 1 for housewife and 0 for other jobs & 0.269 & 0.444 \\
Gender & Dummy variable equaling 1 for male and 0 for female respondents \\
Enviconcern & $\begin{array}{l}\text { Dummy variable equaling 1 for respondents who state their current } \\
\text { concern on environmental issue and 0 otherwise }\end{array}$ & 0.686 & 0.495 \\
Health & $\begin{array}{l}\text { Dummy variable equaling 1 for respondents who state their current } \\
\text { concern on health and food safety and 0 otherwise }\end{array}$ & 0.339 & 0.474 \\
Center & $\begin{array}{l}\text { Dummy variable equaling 1 for respondents in the center area of Can } \\
\text { Tho city and 0 for those in the suburban area of Can Tho city }\end{array}$ & 0.333 & 0.472 \\
\hline
\end{tabular}
Source: Own estimates; data appendix available from authors.

Table 3 shows the results of a Probit analysis of the dichotomous choice responses to the contingent valuation questions. The model 1 is only estimated with the independent variable of bid value, while the model 2 is analyzed including the variables of respondents' demographic characteristics and other important factors affecting the willingness to pay for organic vegetables. The predictive powers of the two models are 
relatively high, with nearly 69 percent in model 1 , and over 71 percent in model 2 . The study also performs there is no multicollinearity among the independent variables in these models because the results estimated by the correlation matrix approach shows that there are no correlations in these independent variables higher than 70 percent (Khai and Yabe, 2013). The coefficients of the bid value in the two models are statistically significant and negative as expected, revealing that an increase in bid amount could reduce the 'yes' response and the existence of the WTP for organic vegetables. The results show an increase in Pseudo Rsquared and the log-likelihood value in the model 2 compared with the model 1, revealing that the parametric fit level of the model 2 is also higher than that of the model 1. The value of Swait-Louviere log-likelihood ratio $^{3}$ is $L R=-2[-225.609-(-202.481)]=46.256$ which is larger than the critical value of Chi-square distribution of 18.475 at the $1 \%$ significance level on 7 degrees of freedom ${ }^{4}$. Thus, the model 2 is a better fit than the model 1 for the data estimation. Thus, Model 2 will be used as the final results for interpretations.

The mean and median WTP for the proposed organic vegetables are calculated utilizing the directly estimated values of the coefficients in the Probit model and applying the equation (7) for the mean and (8) for the median WTP and the estimated results are presented in the low part of Table 3. The estimated mean WTP in the model 2 reveals that the residents in the sample are willing to pay a premium of VND 12,733 per $\mathrm{kg}$ for organic vegetables with the 95\% confidence interval between VND 12,162 - 13,645, accounted for over 59\% higher than the current price of conventional vegetables at VND 8,000 per $\mathrm{kg}$. The study also estimates the median WTP of VND 12,189 , performing a half of respondents certainly agrees to pay a premium of $60 \%$ higher than the price of conventional vegetables, similar to the willingness to pay of consumers in metropolitan areas of Vietnam for Chinese mustard with organically cultivated techniques estimated by Mergenthaler et al. (2009). However, this result is slightly lower than the finding of $70 \%$ reported by Hai et al. (2013). This difference could be possibly explained that consumers in the capital of Hanoi might recognize the benefits of organic agriculture more and then agree to pay a higher premium compared to those in the Mekong Delta.

Table 3: Probit results of willingness to pay for organic vegetables

\begin{tabular}{|c|c|c|c|c|c|c|}
\hline \multirow{3}{*}{ Variables } & \multirow{2}{*}{\multicolumn{2}{|c|}{ Model 1}} & \multicolumn{4}{|l|}{ Model 2} \\
\hline & & & \multicolumn{2}{|c|}{ Probit function } & \multicolumn{2}{|c|}{ Marginal effect } \\
\hline & Coef. & S.E. & Coef. & S.E. & $d y / d x$ & S. E. \\
\hline $\ln ($ Bid $)$ & $-2.3630^{* * *}$ & 0.3615 & $-3.3852^{* * *}$ & 0.4500 & -1.341 & 0.179 \\
\hline Income & & & $0.0917^{* * *}$ & 0.0320 & 0.036 & 0.013 \\
\hline Graduate & & & $0.3064^{*}$ & 0.1751 & 0.120 & 0.068 \\
\hline Housewife & & & $0.4088^{* *}$ & 0.1774 & 0.158 & 0.067 \\
\hline Gender & & & -0.0702 & 0.1649 & -0.028 & 0.065 \\
\hline Enviconcern & & & 0.1305 & 0.1723 & 0.052 & 0.068 \\
\hline Health & & & $0.5850^{* * *}$ & 0.1805 & 0.225 & 0.066 \\
\hline Center & & & $0.5298^{* * *}$ & 0.1969 & 0.205 & 0.073 \\
\hline Constant & $22.2643^{* * *}$ & 3.3892 & $30.7999^{* * *}$ & 4.1674 & & \\
\hline Log likelihood value & -225.609 & & -202.481 & & & \\
\hline Pseudo R-squared & 0.091 & & 0.184 & & & \\
\hline Correct prediction (\%) & 69.444 & & 71.389 & & & \\
\hline Mean WTP & $13,514(12$, & $-15,441)$ & $12,733(12,1$ & $-13,645)$ & & \\
\hline Median WTP & $12,357(11$, & $-13,221)$ & $12,189(11,6$ & $-12,787)$ & & \\
\hline
\end{tabular}

Notes: $* * *, * *, *$ indicate statistical significance at the $0.01,0.05$ and 0.1 level respectively

The 95\% confidence intervals are given in parentheses and estimated using the Krinsky and Robb (1986)

Source: Own estimates; data appendix available from authors.

\footnotetext{
${ }^{3}$ Calculated by the formula $L R=-2\left(L L_{1}-L L_{2}\right)$, where $L L_{\mathrm{x}}$ is the log-likelihood statistics for the different models.

${ }^{4}$ The degrees of freedom are given by the difference in the numbers of parameters estimated in the two models.
} 
The same as the results from other studies (e.g. Yin et al., 2010; Tsakiridou et al, 2008; Loureiro and Hine, 2002), the coefficients of Income, Graduate variables are statistically significant and have a positive sign, suggesting the respondents with higher income are more likely to support the proposed program, and those attending a university or higher agree to pay a higher premium for organic vegetables. The results also show that housewives are more likely to select the proposed organic vegetables. Regarding environmental and healthy motivations, the variables of Enviconcern and Health are dummy variables equaling 1 if a respondent expresses his/her concern on current environmental or health issues, respectively and 0 otherwise. Consistently with the study by Yin et al. (2010), the insignificant parameter of Enviconcern, but the significant positive sign of Health variable reveals that the respondents who care about their health are ready to support the program of organic products, but not correct for those who put a priority for environmental issues. The possible explanation is that they simply think organic products without chemical materials may be safer or better for their health compared with conventional products. Similar to the study by Govindasamy et al., 2008, the coefficient of Center variable is significant and positive, revealing that those who live in the center of Can Tho city are more likely to support the organically produced vegetables.

\section{Conclusion}

The study attempted to use the approach of CV method to recognize the current situation of Mekong Delta consumer's preferences and WTP for organic vegetables. The study showed that the majority of respondents were willing to buy organic vegetables with a price premium of averagely VND 12,733 per $\mathrm{kg}$, about 59\% higher than the market price of conventional vegetables at the same time of study. The study found that the presence of higher income and graduate education of respondents or housewives increase the likelihood a consumer prefers organic vegetables. The respondents with higher health concern who were favorably disposed toward purchasing organically grown vegetables may consider the organic product to be safer or better for health, while increased the environmental concern of consumers does not necessarily translate into a stronger willingness to purchase the organic vegetables. Although the study provided the important analysis of consumers' preferences for organic vegetables that was very little in the Vietnam's literature, our results were only based on a snapshot of Can Tho city consumers in the Mekong Delta that might not represent the preferences of whole Vietnamese consumers and at a single point in time. It would be interesting if additional researches analyze whether the results of our study could be consistent with the bigger sample size for Vietnamese consumers and other organic products, and more in-depth studies should be also done to examine the over-time changes of consumers' preferences for organic programs.

Conflicts of interest: The author declares no conflict of interest.

\section{References}

Bateman, I. J., Langford, I. H., Turner, R. K., Willis, K. G. \& Garrod, G. D. (1995). Elicitation and Truncation Effects in Contingent Valuation Studies. Ecological Economics, 12(2), 161-179. doi: Doi 10.1016/0921-8009(94)00044-V

Carson, R. T., Flores, N. E. \& Meade, N. F. (2001). Contingent valuation: Controversies and evidence. Environmental \& Resource Economics, 19(2), 173-210. doi: Doi 10.1023/A:1011128332243

Dam, N. D., Canh, D. X., Ha, N. T. T., Tan, N. V. \& Thieu, N. D. (2012). Vietnam Organic Agiculture: An overview on current statusand some success activities. Paper presented at the the 4th ANSOFT Workshop Gwangju/ Jeonam, Korea 18-20 October 2012.

Gil, J. M., Gracia, A. \& Sanchez, M. (2000). Market segmentation and willingness to pay for organic products in Spain. The International Food and Agribusiness Management Review, 3(2), 207-226.

Govindasamy, R., DeCongelio, M. \& Bhuyan, S. (2006). An Evaluation of Consumer Willingness to Pay for Organic Produce in the Northeastern U.S. Journal of Food Products Marketing, 11(4), 3-20. doi: 10.1300/J038v11n04_02

Haab, T. C. \& McConnell, K. E. (2002). Valuing Environmental and Natural Resources: The Econometrics of Non-market Valuation: Edward Elgar Publishing.

Hai, N. M., Moritaka, M. \& Fukuda, S. (2013). Willingness to Pay for Organic Vegetables in Vietnam: An Empirical in Hanoi capital. J. Fac. Agr., Kyushu Univ, 58(2), 449-458. 
Hanemann, W. M. (1984). Welfare Evaluations in Contingent Valuation Experiments with Discrete Responses. American journal of agricultural economics, 66(3), 332-341. doi: Doi 10.2307/1240800

Khai, H. V. (2014). The Economic Benefits of Surface Water Quality Improvements: A Case of Channel in the Mekong Delta, Vietnam. The International Journal of Environmental Sustainability, 9(2), 13.

Khai, H. V. \& Yabe, M. (2011). An Analysis of Willingness to Pay for Commodity Insurance of Rice Production in Vietnam. Asia-African Journal of Economics and Econometrics, 11(2), 485-493.

Khai, H. V. \& Yabe, M. (2013). Impact of Industrial Water Pollution on Rice Production in Vietnam. In N. W. T. Quinn (Ed.), International Perspectives on Water Quality Management and Pollution Control (pp. 61-85): InTech Publishing.

Krinsky, I. \& Robb, A. L. (1986). On Approximating the Statistical Properties of Elasticities. Review of Economics and Statistics, 68(4), 715-719. doi: Doi 10.2307/1924536

Laroche, M., Bergeron, J. \& Barbaro-Forleo, G. (2001). Targeting consumers who are willing to pay more for environmentally friendly products. Journal of consumer marketing, 18(6), 503-520.

Loureiro, M. L. \& Hine, S. (2002). Discovering niche markets: A comparison of consumer willingness to pay for local (Colorado grown), organic, and GMO-free products. Journal of Agricultural and Applied Economics, 34(3), 477-488.

Mergenthaler, M., Weinberger, K. \& Qaim, M. (2009). Consumer Valuation of Food Quality and Food Safety Attributes in Vietnam. Review of Agricultural Economics, 31(2), 266-283. doi: DOI 10.1111/j.14679353.2009.01437.x

Ridker, R. G. (1971). Economic Costs of Air Pollution Studies: Praeger Publishers.

Robert, K. D. (1963). The Value of Outdoor Recreation: An Economic Study of the Maine Woods. (PhD dissertation), Harvard University.

Rodriguez, E., Lacaze, V. \& Lupin, B. (2007). Willingness to pay for organic food in Argentina: Evidence from a consumer survey Paper presented at the The 105th EAAE Seminar 'International Marketing and International Trade of Quality Food Products', Bologna, Italy, March 8 -10, 2007.

Roitner-Schobesberger, B., Darnhofer, I., Somsook, S. \& Vogl, C. R. (2008). Consumer perceptions of organic foods in Bangkok, Thailand. Food Policy, 33(2), 112-121. doi: DOI 10.1016/j.foodpol.2007.09.004

Simmons, L. \& Scott, S. (2008). Organic Agriculture and "Safe" Vegetables in Vietnam: Implications for AgroFood System Sustainability. Department of Geography, University of Waterloo, Canada.

Tsakiridou, E., Boutsouki, C., Zotos, Y. \& Mattas, K. (2008). Attitudes and behaviour towards organic products: an exploratory study. International Journal of Retail \& Distribution Management, 36(2), 158-175.

Tsakiridou, E., Zotos, Y. \& Mattas, K. (2006). Employing a Dichotomous Choice Model to Assess Willingness to Pay (WTP) for Organically Produced Products. Journal of Food Products Marketing, 12(3), 59-69. doi: 10.1300/J038v12n03_05

Venkatachalam, L. (2004). The contingent valuation method: a review. Environmental Impact Assessment Review, 24(1), 89-124. doi: Doi 10.1016/S0195-9255(03)00138-0

Wattage, P. (2002). Effective Management Biodiversity Conservation in Sri Lankan Coastal Wetlands: CVM1 Literature Review: University of Portsmouth Cemare, UK.

Yao, R. \& Kaval, P. (2008). Valuing Biodiversity Enhancement in New Zealand Working Paper in Economics 08/07, Economics Department, University of Waikato, Private Bag 3105, Hamilton, New Zealand.

Yin, S. J., Wu, L. H., Du, L. \& Chen, M. (2010). Consumers' purchase intention of organic food in China. Journal of the Science of Food and Agriculture, 90(8), 1361-1367. doi: Doi 10.1002/Jsfa.3936 